Marquette University

e-Publications@Marquette

College of Nursing Faculty Research and

Publications

Nursing, College of

9-1-2017

\title{
Debrief in Emergency Departments to Improve Compassion Fatigue and Promote Resiliency
}

Kristin Haglund

Marquette University, kristin.haglund@marquette.edu

Madeline Schmidt

Marquette University, madeline.schmidt@marquette.edu

Accepted version. Journal of Trauma Nursing, Vol. 24, No. 5 (September/October 2017): 317-322. DOI. (C) 2017 Society of Trauma Nurses. Used with permission. 


\section{Marquette University}

\section{e-Publications@Marquette}

\section{Nursing Faculty Research and Publications/College of Nursing}

This paper is NOT THE PUBLISHED VERSION; but the author's final, peer-reviewed manuscript. The published version may be accessed by following the link in th citation below.

Journal of Trauma Nursing, Vol. 24, No. 5 (September/October 2017): 317-322. DOI. This article is (C) Society of Trauma Nurses and permission has been granted for this version to appear in ePublications@Marquette. Society of Trauma Nurses does not grant permission for this article to be further copied/distributed or hosted elsewhere without the express permission from Society of Trauma Nurses.

\section{Debrief in Emergency Departments to Improve Compassion Fatigue and Promote Resiliency}

Madeline Schmidt

Marquette University College of Nursing, Milwaukee, Wisconsin

Kristin Haglund

Marquette University College of Nursing, Milwaukee, Wisconsin.

\section{Abstract}

The purpose of this case study was to describe compassion fatigue using one nurse's experience as an example and to present the process of Personal Reflective Debrief as an intervention to prevent compassion fatigue in emergency department (ED) nurses. Debriefing after adverse outcomes using a structured model has been used in health care as a nonthreatening and relatively low-cost way to discuss unanticipated outcomes, identify opportunities for improvement, and heal as a group. There are many methods of debrief tailored to specific timing around events, specific populations of health care workers, and amount of time for debriefing. Debrief with personal and group reflection will help develop insights that nurses may need to understand their own emotions and experiences, as well as to develop knowledge that can be used in subsequent situations. Regular engagement in a proactive 
scheduled Personal Reflective Debrief has been identified as a method of promoting resiliency in an environment where the realities of emergency nursing make compassion fatigue an imminent concern. Nurses working in the ED normally experience some level of stress because of high acuity patients and high patient volume; yet, repeated exposure puts them at risk for developing compassion fatigue. The Personal Reflective Debrief is one way emergency nurses can alleviate some of this caring-related stress and thereby become more resilient. Increasing nurses' resilience to workplace stress can counter compassion fatigue. The key is to provide planned, proactive resources to positively improve resiliency.

Keywords: Compassion fatigue; Debrief; Emergency nurses; Resilience

The authors declare no conflicts of interest.

Nurses working in emergency departments (EDs) normally experience some level of stress at work because of high acuity patients and high patient volume; yet, repeated exposure puts them at risk for developing compassion fatigue. Compassion fatigue is defined as an extremely tense feeling experienced by those who care for people who are in distress and is measured by three components: burnout, secondary traumatic stress, and compassion satisfaction (Gentry, 2015). There are ways in which emergency nurses can alleviate some of this caring-related stress and thereby become more resilient. Debrief is one method that has been shown to decrease professional stress and improve concentration, morale, and work engagement (Healy \& Tyrrell, 2013; Sandhu et al., 2014; Tannenbaum \& Cerasoli, 2013). Personal Reflective Debrief (PRD) takes the structure and goals of a debrief and adds personal reflection to deepen and reinforce social support and promote self-reflection among individuals while working in a group setting. Regular engagement in a proactive scheduled PRD may be a method of promoting resiliency in an environment where the realities of emergency nursing make compassion fatigue an imminent concern. Finding a solution for leadership to give staff nurses the support they need becomes essential.

Compassion is a central value of nursing and is included in the first provision of the American Nurses Association (ANA) Code of Ethics (ANA, 2015). Compassion fatigue is made up of three components: compassion satisfaction, secondary traumatic stress, and burnout (Stamm, 2010). Compassion satisfaction is the meaning and joy that nurses get from taking care of patients in their time of need (Stamm, 2010). Secondary traumatic stress is a feeling of despair that can elicit physical or psychological symptoms such as anxiety, sleeplessness, complaining, lack of satisfaction with job, nausea, or depression (Sacco, Ciurzynski, Harvey, \& Ingersoll, 2015). Burnout is directly linked to the work environment and job satisfaction (Sacco et al., 2015). Burnout is the experience of perceived demands that outweigh the perceived resources (Flarity, Gentry, \& Mesnikoff, 2013). Attributes of nurses who are experiencing burnout include feelings of exhaustion, frustration, hopelessness, or depression. It is the balance of all three components that leads to compassion fatigue.

The cumulative effects of compassion itself can cause compassion fatigue (Emergency Nurses Association [ENA], 2014; Lachman, 2016; Makic, 2015). Risk factors for developing compassion fatigue can vary by health care profession because of different patient care interactions, different patient ratios, and different role-related stresses (Sorenson, Bolick, Wright, \& Hamilton, 2016). External stressors such as overcrowding, pressure to improve flow, patient satisfaction, and fiscal goals of the organization, coupled with experiencing critical incidents, put ED nurses at higher risk for developing 
compassion fatigue (ENA, 2014). Nurses who provide care to traumatized individuals can have intense and painful emotional responses. If nurses do not recognize and process these emotions in a healthy way, they can develop compassion fatigue (Sorenson et al., 2016). Nurses may develop symptoms of compassion fatigue as a result of the cumulative effect of external stressors, caring for traumatized patients, inadequate emotional self-care that leads to a situational loss of empathy, loss of satisfaction in one's work or career, and burnout (Flarity et al., 2013; Hevezi, 2015; Hinderer et al., 2014; Hunsaker, Chen, Maughan, \& Heaston, 2014). The purpose of this article was to describe compassion fatigue using one nurse's experience as an example and to present the process of PRD as an intervention to prevent compassion fatigue in ED nurses.

\section{ONE NURSE'S STORY}

Having been a nurse for 10 years, I thought that by blocking out the emotions I felt while working in this extremely busy ED with the complexity of patients was making me a better nurse; I now realize that I was burned out, exhausted, and lacked any empathy for my patients' situations. The day I made a medication error started out as a regular shift in the ED: multiple patients, a filled waiting room, and a tight staff; this particular shift, however, caused me to have more stress than normal. I had worked 7 days in a row and was mentally fatigued from keeping up that pace. Life outside of work was such a mess and I hadn't had any time to attend to it, so I was constantly thinking about things I needed to do. The patients this day were the last thing on my mind. I couldn't concentrate! Although I had other patients, one particularly critically ill patient distracted me so much that I made a medical error.

A woman and her husband came in by ambulance. The moment I saw her, I knew she was sick. I just didn't know exactly what was wrong and I couldn't anticipate the plan of care. I was already feeling burned out about this day, and she became just another patient to me. I think this may be one of the scariest things about being an ED nurse. I wanted to care more, but at that moment, I had no empathy left for her situation; she was like all the other patients.

The patient's skin was gray, and her hands and feet were mottled and blotchy. She was groggy and unable to answer any questions. She had abrasions and bruising all over her body, all in multiple stages of healing. Her blood pressure measured about 60 by palpation. I immediately called a critical care team. The nurses, techs, and a physician rushed in and were asking what I needed them to do. I asked for i.v. starts, blood draws, urine samples, vital signs, an electrocardiogram, and a multitude of other tests and tasks to be completed. The team began to help me, but all of a sudden, another trauma was called. I was left by myself in the room. On most days I could handle this, but I had been feeling burned out for a while and it was all coming too fast.

As the orders came in from the physician, I knew I was beginning to lose control of the situation. I couldn't keep up. I didn't know what to do first. My other patients needed attention, and my phone wouldn't stop ringing. The physician ordered i.v. fluids and vasopressors. Both bags were primed when the physician came back in to tell me not to hang the vasopressor. The patient's blood pressure began to improve on its own. I verbally agreed and hung the fluids on the i.v. pump? or so I thought. Fifteen minutes later, the pump began to beep. I looked over, wondering why this happened because a liter bolus takes about $1 \mathrm{hr}$ to infuse. My heart sank when I realized the entire bag of the vasopressor had been infused. I had hung the vasopressor instead of the i.v. fluid. I ran to the nurses' station to call the 
physician. I began to cry. I had to sit down. I literally began to develop hives on my body. Two other nurses took over care of the patient as I attempted to compose myself. The patient was ok and made it to the intensive care unit, but for a long time, I couldn't help but think it was my fault. I cried at home about it, I beat myself up for weeks internally about it, and I had nightmares. I tried to go to work a few days later, but just seeing the beds in the ED full and the waiting room full, my pager constantly going off, and the ambulances rolling in, I began to hyperventilate and had to go home. Psychologically, I wasn't sure I was cut out for the job anymore; I began to doubt myself all the time. It was hard, and I felt that I had no one to talk to about this; I was bottling up all these emotions and fears inside.

Before this happened, I didn't know that I was experiencing the symptoms of compassion fatigue. It took reflecting on this incident to give my feelings a name: compassion fatigue. I finally began to talk with my colleagues. During a debrief session, I spoke to other nurses, physicians, and pharmacists about my feelings. They all helped me realize that it was not from something I had done but from a combination of factors outside my control. These things didn't change the fact that I had made an error. I knew that was something I had to own up to. However, being able to talk with others about my feelings undoubtedly helped me conclude that I could STILL be an ED nurse. I was able to attend to my symptoms and utilize resources at my hospital for self-care that were discussed during the debrief session. It took some time, but I became better at talking about my feelings and being a better caregiver because I understood myself better and had the support of colleagues. I was not alone. I became compassionate again! I know that I am a GOOD ED nurse. And that I am human? which makes me capable of errors. This will surely not be my last mistake in life or the last time I am frustrated at work in my career as a nurse. I have learned how to be a better nurse from this incident. I wish that someone had been looking out for these symptoms before a mistake was made. I wish I had learned what they were and how to combat them. As a result of this incident, time to reflect with my coworkers, the ability to debrief as a team, and my recognition of the self-care that I need, I now know that resiliency is possible and that my caring can be compassionate again. We are all in this together.

The nurse in this example was experiencing symptoms of compassion fatigue. Signs and symptoms of compassion fatigue feelings (see Table 1) can be experienced on varying levels. Psychological symptoms include anxiety, avoidance, hyperarousal, memory problems, poor concentration, poor judgment, intrusive thoughts, and lack of compassion (Boyle, 2011; ENA, 2014; Makic, 2015). Symptoms can impact providers' functioning in their personal lives, which worsens the effects of compassion fatigue in the workplace (Berg, Harshbarger, Ahlers-Schmidt, \& Lippoldt, 2016; Crowe, 2016; Sorenson et al., 2016). Adverse experiences in nurses' personal lives can also increase their risks for developing compassion fatigue at work. Personal experiences can alter the risks for compassion fatigue; thus, nurses who may be exposed to similar stressors at work will not experience consequences of occupational stress in the same way and not all of them will develop compassion fatigue (Boscarino, Adams, \& Figley, 2010; Pearlin, 1989).

Nurses' personal resilience can also change the risk for compassion fatigue. Resilience is the ability to positively adjust to difficult times. Resilience is the ability to cope successfully despite adversity (Earvolino-Ramirez, 2007). Resilient people exhibit characteristics that include developing secure attachments with others, effectively engaging in the support of others, creating personal goals, being self-efficacious, and managing stress by a strengthening effect (Polk, 1997). Resilient people are likely 
to view stressors as challenges and opportunities. In addition, they demonstrate commitment and can successfully recognize and control their personal limitations (Polk, 1997). Previously, resilience was considered a personality trait; now, it is seen as a dynamic, modifiable process (Luthar, Cicchetti, \& Becker, 2000; Polk, 1997). Increasing nurses' resilience to workplace stressors can counter compassion fatigue (Tubbert, 2016). Interventions that promote resiliency among nurses include self-regulation, intentionality, self-validation, connection, and self-care (Polk, 1997; Potter et al., 2013). Resiliency can be strengthened through multiple interventions that are tailored to individuals' characteristics; psychosocial attributes, intrinsic and extrinsic factors, situational patterns, or philosophical meanings (Polk, 1997). The theory of resilience suggests that individuals can develop personally meaningful protective measures that can be used when encountering adversity to bring about a positive emotional outcome (Greene, Galambos, \& Lee, 2003). In the context of the nurse's story, the meaningful reflection and social support she received through the use of debrief after the adverse event may provide protection for her in the future with adverse events. When a meaningful intervention can provide nurses with tools they can use to protect themselves from stressful workplace events, then there will be less burnout, turnover, and decreased job satisfaction.

Leaders have unique opportunities to intervene early and often to provide staff with strategies they need to find satisfaction in their work environment and in the nursing care they provide. Leaders should routinely evaluate their nursing staff for signs of compassion fatigue through observations, conversations, and use of validated tools such as the Professional Quality of Life Scale (Stamm, 2010), Holmes-Rahe Life and Stress Inventory (Holmes \& Rahe, 1967), or Secondary Traumatic Stress Scale (Bride, Robinson, Yegidis, \& Figley, 2004). Signs that nurses may be struggling with can be observed through absenteeism, decreased productivity, and errors. Nurses who are experiencing compassion fatigue may report to leadership their lack of joy and empathy toward patients, decreased productivity, and errors (ENA, 2014). High turnover may indicate that many nurses in the institution, or on a certain unit, are suffering from compassion fatigue (ENA, 2014).

Some strategies that leaders may use to diminish compassion fatigue include education, self-care activities, reflection, and debrief (Flarity et al., 2013; Hevezi, 2015; Kelly, Runge, \& Spencer, 2015). Nurses need education regarding the signs and symptoms of compassion fatigue so that they can take better care of themselves and their coworkers. The ANA Code of Ethics states that nurses owe the same duty to themselves as they do to others, including preservation of self, and continued professional and personal goals (ANA, 2015). By embracing healthy practice behaviors and engaging in self-care activities, nurses can nurture their own physical and emotional needs and can improve nursing practice (Makic, 2015). Nurses can combat compassion fatigue by creating supportive work environments (Boyle, 2011).

In one study of a self-care activity, meditation was used to proactively impact feelings of compassion fatigue (Hevezi, 2015). Scores on a validated Professional Quality of Life Scale (ProQOL) showed a decreased level of compassion fatigue and an improvement in resiliency among nurses (Flarity et al., 2013; Hevezi, 2015; Kelly et al., 2015; Stamm, 2010). Reflection is a way of developing insight into experiences and increasing knowledge that can be used in similar situations in the future. Debriefing can be done after critical incidents, simulations, and other adverse outcomes to identify goals, diminish acute symptoms, foster small group discussions, and provide closure (Rivera-Chiauzzi, Lee, \& Goffman, 
2016). Regular engagement in debriefing has been identified as an intervention that can be used in areas of nursing where compassion fatigue is of concern (Berg et al., 2016). Reflection and debrief can be combined to help nurses manage their reactions to experiences individually, decrease feelings of isolation by working together as a group, and together provide coping mechanisms for healing and improving resiliency (Kessler, Cheng, \& Mullan, 2015). If these strategies are utilized in practice proactively, instead of reactively, nurses will become increasingly more aware of the feelings of compassion fatigue.

\section{DEBRIEF}

Originally used in the military to improve learning performance, debrief has been used in other areas including health care (Magyar \& Theophilos, 2010; Tannenbaum \& Cerasoli, 2013). Debriefing after adverse outcomes using a structured model has been used in health care as a nonthreatening and relatively low-cost way to discuss unanticipated outcomes, identify opportunities for improvement, and heal as a group (Rivera-Chiauzzi et al., 2016; Tannenbaum \& Cerasoli, 2013). Debriefing is a powerful tool that is underutilized at many hospitals; yet, The Joint Commission recommends using debriefs to improve teamwork and communication (Healy \& Tyrrell, 2013; Rivera-Chiauzzi et al., 2016; Salas et al., 2008). Essential elements of debrief include active learning, a focus on specific events, team support, and goals (Tannenbaum \& Cerasoli, 2013). There are several styles of debrief tailored to specific timing around events, specific populations of health care workers, and amount of time for debriefing. Debrief with personal and group reflection will help nurses understand their own emotions and experiences and develop knowledge that can be used in subsequent situations. Debriefs promote individual learning, through group sharing and bonding, which are beneficial in combating compassion fatigue (Gentry, Baggerly, \& Baranowsky, 2004; Jackson, Firtko, \& Edenborough, 2007). Critical incident stress debriefing, didactic debriefs, and psychological debriefs have all been seen as methods that can meet the needs of health care workers (Figley, 1995).

There are obstacles to using a debrief including lack of time and lack of a structured plan (Sandhu et al., 2014). With most structured models of debrief, finding staff who are prepared to lead the debrief sessions can be difficult (Healy \& Tyrrell, 2013). To overcome obstacles, and increase use, any debrief method should include the essential elements of debriefing and be scheduled for a reasonable time of day and duration and be offered on a regular basis. Each time debrief is offered, it should be educational, comfortable, and focus on a limited number of issues. The debrief leaders should be supportive; educated on the structure and goals of the session; model feedback; and include conclusion, goals, and follow-up to prevent the debrief from becoming a discussion without a purpose. When debriefing a critical incident, there is a possibility that the debrief could increase nurses' psychological stress and symptoms (Magyar \& Theophilos, 2010). Having a group leader who is a trained professional is one way to prevent an outcome of increased stress from the debrief.

\section{PERSONAL REFLECTIVE DEBRIEF}

Personal Reflective Debrief is an individually focused specific debrief method of structured reflection, learning, and healing that includes the essential elements of a debrief, namely, personal reflection, opportunities for personal development through education and encouragement, and activities to promote resiliency and proactive coping methods. Reflection activities may include guided discussion, 
time for a written reflection during the session, and instructions for a written reflection to be done either before or after the session. Sample instructions for a reflection include asking participants to describe a recent stressful event at work as factually as possible, evaluate what went well, and what they would change next time.

Participating in regular, rejuvenating activities, strong positive peer support, and growth of perceptual maturation through minimizing the internalization of the work environment and focusing on compassionate nursing care are examples of activities to promote resilience (ENA, 2014). A PRD could be used to process a critical incident within $24 \mathrm{hr}$ of the event if needed. For an ED nurse, there are many stressful aspects of care in addition to individual critical incidents that could be addressed in debrief sessions such as overcrowding, workplace violence, home stress, and a lack of feeling of appreciated by patients and their families. Developing a scheduled regular offering of a PRD from leadership, such as every 3 months, could proactively provide emotional release for individuals as part of a supportive team, help nurses and leaders recognize the emotional symptoms of compassion fatigue early, and facilitate early intervention for group and for individuals. For successful implementation, the PRD should be called after the shift and be announced well ahead of time so that nurses can schedule and plan to stay. Incentives for participation may be offered initially while the process is new to staff. The PRD should last no more than $30 \mathrm{~min}$. All participants are encouraged to participate when part of the group so that all voices can be heard and social learning can occur.

\section{CONCLUSION}

The case example in this article demonstrates the need for an established, proactive PRD session. If the nurse in this case had understood what her feelings meant, she might have been able to recognize that she was suffering from compassion fatigue and taken steps to reduce her chronic stress before the error was made. As the incidences of high acuity patients and high volume are frequent occurrences in the ED, nurses need the opportunity to have a regularly scheduled PRD to consistently promote and reinforce the feelings of resiliency to compassion fatigue. By supporting staff nurses and preventing secondary stress and burnout, leadership can improve outcomes. With the support of management, nurses who are able to recognize and identify their own situations early will have better resiliency (Morrison \& Joy, 2016). Providing PRD for staff can contribute to improved morale, decreased turnover, and better patient care interactions (Berg et al., 2016; Kessler et al., 2015). Managers who are aware of secondary traumatic stress symptoms and can recognize this form of occupational stress early can intervene to promote psychological well-being of their staff (Morrison \& Joy, 2016). Fostering a positive organizational culture in the workplace is a way that leaders may improve resilience among nurses (Hart, Brannon, \& DeChesnay, 2014).

The problem of compassion fatigue continues to exist, although the approach to prevention can be changed and be more proactive. To better understand levels of compassion fatigue among nurses, more information could be gathered with valid survey tools that specifically assess the components of compassion fatigue. Research could include analyzing the effectiveness of the PRD in practice, evaluating the appropriate time frame needed for the intervention, large sample sizes, matching preand posttest compassion fatigue evaluation scores, and evaluation over long periods of time. Over time, repeated measures of resiliency may show the effect of this work environment intervention. By offering a PRD a few times a year, with space between surveys, leaders could assess the needs of their 
staff, the effects of the various activities included in the debrief, and the overall benefits of this intervention. Showing support in the work environment can promote resiliency even within the most demanding health care organization. The future of nursing requires increased awareness about compassion fatigue and a culture that promotes resiliency, so nurses can continue to provide the compassionate care they entered this profession to provide.

\section{KEY POINTS}

- Many nurses experience symptoms of compassion fatigue at some point in their career, which can lead to burnout and job dissatisfaction.

- Compassion fatigue may be prevented by engaging in proactive, planned reflective debriefs.

- Health care leaders who advocate for planned activities to promote resiliency among their nursing staff can increase retention and morale.

\section{TABLE 1 Indicators of Compassion Fatigue}

\begin{tabular}{|l|l|}
\hline Domain & Indicators \\
\hline Psychological & $\begin{array}{l}\text { Anxiety; anger, cynical thoughts; sense of loss of meaning; racing thoughts; feelings } \\
\text { of hating one's work }\end{array}$ \\
\hline Physical & $\begin{array}{l}\text { Gastrointestinal distress; weight changes; sleep problems; somatic complaints; } \\
\text { fatigue }\end{array}$ \\
\hline Behavioral & $\begin{array}{l}\text { Self-medicating; substance abuse; disordered eating; irritable; impaired } \\
\text { communication in relationships; reactivity; isolation; frequent absenteeism; } \\
\text { increased complaining }\end{array}$ \\
\hline
\end{tabular}

Note. From Certified Compassion Fatigue Professional Training [PowerPoint Slides], by E. Gentry, 2015. Retrieved from http://ccfp.kajabi.com/posts/segment-3-tools-for-hope. Adapted with permission.

\section{Note}

For more than 96 additional continuing education articles related to emergency care topics, go to NursingCenter.com/CE.

\section{REFERENCES}

American Nurses Association [ANA]. (2015). Code of ethics for nurses with interpretive statements. Retrieved from http://www.nursingworld.org/MainMenuCategories/EthicsStandards/CodeofEthicsforNur ses/Code-of-Ethics-For-Nurses.html

Berg G. Harshbarger J. Ahlers-Schmidt C. Lippoldt D. (2016). Exposing compassion fatigue and burnout syndrome in a trauma team: A qualitative study. Journal of Trauma Nursing , 23 (1), 3 - 10. doi:10.1097/JTN.0000000000000172

Boscarino J. Adams R. Figley C. (2010). Secondary trauma issues for psychiatrists: Identifying vicarious trauma and job burnout. Psychiatric Times , 27 (11), 24 - 26.

Bride B. Robinson M. Yegidis B. Figley C. (2004). Development and validation of the secondary traumatic stress scale. Research on Social Work Practice , 14 (1), 27 - 35. 
Boyle D. (2011). Countering compassion fatigue; A requisite nursing agenda. Online Journal of Issues in Nursing , 16 (1). doi:10.3912.OJIN.Vol16No01Man022

Crowe L. (2016). Identifying the risk of compassion fatigue, improving compassion satisfaction and building resilience in emergency medicine. Emergency Medicine Australia , 28 , 106 - 108. doi:10.1111/1742-6723.12535

Earvolino-Ramirez M. (2007). Resilience: A concept analysis. Nursing Forum , 42 (2), 73 - 82.

Emergency Nurses Association [ENA]. (2014). Topic brief: Compassion fatigue. Retrieved from https://www.ena.org/practice-research/Practice/Documents/CompassionFatigue.pdf

Figley C. (1995). Compassion fatigue; Coping with secondary traumatic stress disorder in those who treat the traumatized. New York, NY : Brunner/Mazel.

Flarity K. Gentry J. Mesnikoff N. (2013). The effectiveness of an educational program on prevention and treating compassion fatigue in emergency nurses. Advanced Emergency Nursing Journal , 35 (3), 247 - 258. doi:10.1097/TME.0b013e31829b726f

Gentry E. (2015). Certified compassion fatigue professional training [PowerPoint slides]. Retrieved from http://ccfp.kajabi.com/posts/segment-3-tools-for-hope

Gentry E. Baggerly J. Baranowsky A. (2004). Training-as-treatment: Effectiveness of the certified compassion fatigue specialist training. International Journal of Emergency Mental Health , 6 (3), 147 - 55.

Greene R. Galambos C. Lee Y. (2003). Resilience theory: Theoretical and professional conceptualizations. Journal of Human Behavior in the Social Environment , 8 (4), 75 - 91. doi:10.1300/J137v08n04_05

Hart P. Brannon J. DeChesnay M. (2014). Resilience in nurses: An integrative review. Journal of Nursing Management , 22 , 720 - 734. doi:10.1111/j.1365-2834.2012.01485.x

Healy S. Tyrrell M. (2013). Importance of debriefing following critical incidents. Emergency Nurse , 20 (10), 32 - 37.

Hevezi J. (2015). Evaluation of a meditation intervention to reduce the effects of stressors associated with compassion fatigue among nurses. Journal of Holistic Nursing , 34 (4), 343 - 350. doi:10.1177/0898010115615981

Hinderer K. VonRueden K. Friedmann E. McQuillan K. Gilmore R. Kramer B. (2014). Burnout, compassion fatigue, compassion satisfaction, and secondary traumatic stress in trauma nurses. Journal of Trauma Nursing , 21 (4), 160 - 169. doi:10.1097/JTN.0000000000000055

Holmes T. Rahe R. (1967). The social readjustment rating scale. Journal of Psychosomatic Research , 11 (2), $213-218$.

Hunsaker S. Chen H. Maughan D. Heaston S. (2014). Factors that influence the development of compassion fatigue, burnout, and compassion satisfaction in emergency department nurses. Journal of Nursing Scholarship , 47 (2), 186 - 194. doi:10.1111/jnu.12122

Jackson D. Firtko A. Edenborough M. (2007). Personal resilience as a strategy for surviving and thriving in the face or workplace adversity: A literature review. Journal of Advanced Nursing , 60 (1), 1 9. doi:10.1111/j.1365-2648.2007.04412.x

Kelly L. Runge J. Spencer C. (2015). Predictors of compassion fatigue and compassion satisfaction in acute care nurses. Journal of Nursing Scholarship , 47 (6), 522 - 528. doi:10.1111/jnu.12162 
Kessler D. Cheng A. Mullan P. (2015). Debriefing in the emergency department after clinical events: A practical guide. Annals of Emergency Medicine , 65 (6), 690 - 698. doi:10.1016/j.annemergmed.2014.10.019

Lachman V. (2016). Compassion fatigue as a threat to ethical practice: Identification, personal and workplace prevention/management strategies. Medsurg Nursing , 25 (4), 275 - 278.

Luthar S. Cicchetti D. Becker B. (2000). The construct of resilience: A critical evaluation and guidelines for future work. Child Development , 71 (3), 543 - 562.

Magyar J. Theophilos T. (2010). Review article: Debriefing critical incidents in the emergency department. Emergency Medicine Australasia , 22 , 499 - 506. doi:10.1111/j.17426723.2010.01345.x

Makic M. (2015). Taking care of the caregiver: Compassion satisfaction and compassion fatigue. Journal of Perianesthesia Nursing , 30 (6), 546 - 547. doi:10.1016/j.jopan.215.09.006

Morrison L. Joy J. (2016). Secondary traumatic stress in the emergency department. Journal of Advanced Nursing , 72 (11), 2894 - 2906. doi:10.1111/jan.13030

Pearlin L. (1989). The sociological study of stress. Journal of Health and Social Behavior , 30 (3), 241 256.

Polk L. (1997). Toward a middle-range theory of resilience. Advances in Nursing Science , 19 (3), 1 - 13.

Potter P. Deshields T. Berger J. Clarke M. Olsen S. Chen L. (2013). Evaluation of a compassion fatigue resiliency program for oncology nurses. Oncology Nursing Forum , 40 (2), 180 - 187. doi: 10.1188/13.ONF.180-187

Rivera-Chiauzzi E. Lee C. Goffman D. (2016). Debriefing after adverse outcomes: An opportunity to improve quality and patient safety. Contemporary OBGYN. Retrieved from http://contemporaryobgyn.modernmedicine.com/contemporary-obgyn/news/debriefingafter-adverse-outcomes-opportunity-improve-quality-and-patient-safetye?page=0,3

Sacco T. Ciurzynski S. Harvey M. Ingersoll G. (2015). Compassion satisfaction and compassion fatigue among critical care nurses. Critical Care Nurse , 35 (4), 32 - 43. doi: 10.4037/ccn2015392

Salas E. Klein C. King H. Salisbury M. Augenstein J. Birnbach D. Upshaw C. (2008). Debriefing medical teams: 12 evidence-based best practices and tips. The Joint Commission Journal on Quality and Patient Safety , 34 (9), 518 - 527.

Sandhu N. Eppich W. Mikrogianakis A. Grant V. Robinson T. Cheng A. (2014). Postresuscition debriefing in the pediatric emergency department: A national needs assessment. Canadian Journal of Emergency Medicine , 16 (5), 383 - 392. doi:10.2310/8000.2013.131136

Sorenson C. Bolick B. Wright K. Hamilton R. (2016). Understanding compassion fatigue in healthcare providers: A review of current literature. Journal of Nursing Scholarship , 48 (5), 456 - 465. doi:10.1111/jnu.12229

Stamm B. H. (2010). The concise ProQOL manual (2nd ed.). Pocatello, ID : ProQOL.org.

Tannenbaum S. Cerasoli C. (2013). Do team and individual debriefs enhance performance? A metaanalysis. Human Factors , 55 (1), 231 - 245. doi:10.1177/0018720812448394

Tubbert S. (2016). Resiliency in emergency nurses, Journal of Emergency Nursing , 42 (1), 47 - 52. doi: 10.1016/j.jen.2015.05.016 